\title{
NOTE
}

\section{Outbreaks of an ulcerative and haemorrhagic disease in Arctic char Salvelinus alpinus caused by Aeromonas salmonicida subsp. smithia}

\author{
E. Goldschmidt-Clermont ${ }^{1}$, O. Hochwartner ${ }^{2}$, A. Demarta ${ }^{3}$, A.-P. Caminada ${ }^{3}$, \\ J. Frey ${ }^{1, *}$
}

\begin{abstract}
${ }^{1}$ Institute of Veterinary Bacteriology, Vetsuisse Faculty, Laengassstrasse 122, 3012 Berne, Switzerland
${ }^{2}$ Schwarzenhaidestr. 41, 1230 Vienna, Austria

${ }^{3}$ Cantonal Institute of Microbiology, Via Mirasole 22A, 6500 Bellinzona, Switzerland
\end{abstract}

\begin{abstract}
Arctic char Salvelinus alpinus farmed in different places in Austria and free of the viral diseases viral haemorrhagic septcaemia (VHS), infectious haematopoietic necrosis (IHN) and infectious pancreatic necrosis (IPN) experienced disease and mortality. Diseased fish showed skin ulceration and pathological signs of sepsis. Aeromonas sp. was isolated as pure culture from the kidney of freshly euthanized diseased fish. Three independent isolates from outbreaks that occurred on 2 of the affected farms were analyzed phylogenetically by DNA sequence analysis of the rrs and gyrB genes and phenotypically with biochemical reactions. All 3 isolates were identified as Aeromonas salmonicida subsp. smithia. Analysis of virulence genes in these isolates revealed the presence of a Type III secretion system as well as several related virulence effector genes including aex $T$, encoding the Aeromonas exotoxin AexT, аорP and аорH. These genes are characteristic for virulent strains of typical and atypical subspecies of A. salmonicida.
\end{abstract}

KEY WORDS: Aeromonas salmonicida subsp. Smithia - Arctic char - Bacterial septicaemia . Ulcerative, haemorrhagic disease

\section{INTRODUCTION}

Arctic char Salvelinus alpinus has been reared under farming conditions in Austria since 1990 as a fish for consumption because of its high content of valuable polyunsaturated fatty acids such as $\omega-3$ and $\omega-6$ that are essential in human nutrition (Singer 2007). Eggs are imported from Sweden, disinfected (Actomar ${ }^{\circledR} \mathrm{K}$ 30, polyvinylpyrrolidone-iodide-iodine-complex, $15 \mathrm{ml}$ $\mathrm{l}^{-1}$ for $20 \mathrm{~min}$ ) and hatched locally. Fingerlings up to a market size fish of $600 \mathrm{~g}$ are reared in earth ponds with wooden walls. Fish are fed commercial food for salmonids enriched with cold-extruded seed oil as well as vitamin $\mathrm{C}$ and $\mathrm{E}$. Of the 2 farms in this study, Farm A receives its water supply from a river (water tempera- ture ranging from 4 to $16^{\circ} \mathrm{C}$ ) and Farm B from welland groundwater (water temperature $\max .15^{\circ} \mathrm{C}$ ). All farms were regularly checked and shown to be free of viral haemorrhagic septicaemia (VHS), infectious haematopoietic necrosis (IHN) and infectious pancreatic necrosis (IPN) using standard virological methods. During 2002 to 2008 several outbreaks of a bacterial septic disease occurred from July to October at water temperatures ranging from 8 to $16^{\circ} \mathrm{C}$. Slow growing Gram-negative bacteria which produced tiny colonies on standard blood agar medium were isolated from kidney of moribund fish.

Aeromonas salmonicida is a bacterial species known to cause various diseases including systemic infections as well as ulcerative diseases in a number of different 
fish species. The species A. salmonicida comprises 5 subspecies. A. salmonicida subsp. salmonicida is known as typical $A$. salmonicida, causing furunculosis in salmonid fish (Munro \& Hastings 1993, Bernoth 1997). Atypical A. salmonicida include subsp. smithia, subsp. masoucida, subsp. achromogenes and subsp. pectinolytica which, with the exception of A. salmonicida subsp. pectinolytica, are found as pathogens in a wide variety of fish species (Gudmundsdottir 1998).

\section{MATERIALS AND METHODS}

Bacterial diagnostics. Routine pathological examination of dead and euthanized moribund fish was performed. Fish were killed by immersion in a solution of buffered 3-aminobenzoic acid ethyl esther (MS-222 ${ }^{\circledR}$, Argent Chemical Laboratories). Bacterial samples were taken from the kidney and the skin lesions of freshly euthanized moribund fish, plated on tryptic soy agar plates with $5 \%$ sheep blood (Oxoid) and incubated for 4 to $5 \mathrm{~d}$ at $18^{\circ} \mathrm{C}$. Three isolates originating from kidney of fish from 3 different outbreaks were cloned and sub-cultivated for further analysis.

All 3 strains were identified genetically to the species level using rrs (16S rRNA) gene sequence analysis by PCR amplification of a $1.4 \mathrm{~kb}$ segment of rrs with universal primers and DNA sequence analysis of 1360 bp thereof, as described by Kunhert et al. (2002). To differentiate subspecies of Aeromonas salmonicida, biochemical reactions were performed as described (Martin-Carnahan \& Joseph 2005) for all 3 field strains (JF4097, JF4439 and JF4460) as well as for the type strains of $A$. salmonicida subsp. salmonicida (ATCC $33658^{\mathrm{T}}$ ), A. salmonicida subsp. achromogenes (NCIMB $\left.1110^{\mathrm{T}}\right)$, A. salmonicida subsp. smithia (NCIMB $13210^{\mathrm{T}}$ ) and A. salmonicida subsp. masoucida (ATCC 27013 ${ }^{\mathrm{T}}$ ) that are currently found as fish pathogens. All strains were tested for beta-haemolysis, oxidase, aesculin hydrolysis, fermentation of and gas production from Dglucose, fermentation of sucrose and of D-mannitol, tryptophanase (indole) and production of brown diffusible pigment when cultivated on Luria-Bertani agar. Biochemical reactions were performed at $18^{\circ} \mathrm{C}$ on specific media.

Molecular genetic analysis of Aeromonas sp. To confirm the phenotypic identification, the field strains were submitted to a phylogenetic analysis based on the DNA gyrase subunit B gene gyrB (Yáñez et al. 2003). In brief, gyrB was amplified using oligonucleotide primers UP-1 (GAA GTC ATC ATG ACC GTT CTG CAY GCN GGN GGN AAR TTY GA) and UP-2r (AGC AGG GTA CGG ATG TGC GAG CCR TCN ACR TCN GCR TCN GTC AT) that amplify a $1.1 \mathrm{~kb}$ fragment of gyrB corresponding to positions 346 to 1447 of gyrB of
Escherichia coli K-12. Subsequently the amplified fragment was sequenced with primers UP-1, UP-2r and the following internal primers UP-1S (GAA GTC ATC ATG ACC GT TCT GCA), UP-2Sr (AGC AGG GTA CGG ATG TGC GAG CC), UP3 (ACT ACG AGA TCC TGG CCA AG), UP4 (TCC TCC CAG ACC AAG GAC), UP5r (GCC TTC TTG CTG TAG TCC TCT) and UP6r (GCA GAG TCC CCT TCC ACT ATG TA). The phylogenetic relationships of the $A$. salmonicida subsp. smithia field strains with the other A. salmonicida subspecies, based on gyrB sequences, were analyzed in detail using multiple sequence alignments using the CLUSTAL W software of MEGA version 4 (Ibrahim et al. 1985). Sequence accession numbers used are: A. salmonicida subsp. smithia NCIMB13210 ${ }^{\mathrm{T}}$, AM262159; A. salmonicida subsp. smithia JF4097, JF4439 and JF4460, FN394064; A. salmonicida subsp. achromogenes NCIMB1110 ${ }^{\mathrm{T}}$, AM262161; A. salmonicida subsp. salmonicida ATCC33658 ${ }^{\mathrm{T}}$, AY294485; A. salmonicida subsp. salmonicida A449, CP000644; A. salmonicida subsp. masoucida ATCC27013 ${ }^{\mathrm{T}}$ AM262160; $A$. salmonicida subsp. masoucida CECT896, AY101784; A. salmonicida subsp. salmonicida CECT894, AY987517; A. hydrophila hybridization group HG3 CDC0434-84, AF417624; A. salmonicida subsp. pectinolytica $\mathrm{DSM}^{2609}{ }^{\mathrm{T}}, \mathrm{AM} 262158 ;$ A. salmonicida subsp. pectinolytica DSM12609 ${ }^{\mathrm{T}}$, AY101810. A phylogenetic tree of the $g y r B$ sequences was constructed using the neighbour-joining method with genetic distances computed by employing Kimura's 2-parameter method (MEGA version 4).

Analysis of virulence genes. In order to study in more detail the determinants that make Aeromonas salmonicida subsp. smithia a virulent pathogen, we analyzed the 3 field strains isolated in this study by PCR for the presence of the major virulence genes that are known in A. salmonicida (Burr \& Frey 2007). The presence of a Type III secretion system was assessed by the detection of the $\operatorname{asc} V$ gene, which encodes a constitutive protein of the inner ring of the Type III secretion apparatus. Other genes encoding effector proteins translocated via the Type III secretion system were tested: aexT encoding the ADP ribosylase Aeromonas exotoxin T (Fehr et al. 2007), aopP encoding the effector protein that blocks the translocation of NFKB into the host cell's nucleus (Fehr et al. 2006), aopO encoding a putative serine/threonine protein kinase, and aopH encoding a putative tyrosine phosphatase (Dacanay et al. 2006). All genes, ascV, aexT, aоpP, аорO and aopH were detected by a specific PCR assay using the following primers AslcrD-L (GCC CGT TTT GCC TAT CAA), AslcrD-R (GCG CCG ATA TCG GTA CCC) for ascV; RASEXOS-L (GGC GCT TGG GCT CTA CAC), RASEXOS-R (GAG CCC GCG CAT CTT CAG) for aexT; AsORF28 (GAG AGT TGG CTA 
GCG GTG AG), AsORF38 (TCC TCA TGG AGC GCA TCC AG) for aopP; AopO-fwd (CGA GAC AGA CAA GTT TGC), AopO-rev TGT CGT TGT GGA CTA TCC) for aopO; AopH-fwd (TCA ATC AGG ACG ATG TCG), AopH-rev (GTT GGC ATT GAG ATC TGC) for aоpH as previously described (Burr \& Frey 2007). A. salmonicida subsp. salmonicida strain JF2267 was used as positive and the non-pathogenic A. salmonicida subsp. pectinolycita strain DSM 12609 as negative controls.

\section{RESULTS}

Pathological findings on affected fish included haemorrhage in the eye, opaque lens, inflammation in the ventral part of the opercula, skin erosion, fin lesion, pale gills, swelling of spleen and kidney, pale liver and serosal petechiae (Fig. 1). Diseased fish, except those used for bacteriological analyses, were treated successfully with oxytetracycline-medicated feed $(8 \mathrm{~g}$ oxytetracycline $\mathrm{kg}^{-1}$ feed during 12 consecutive days.

Case 1 was a moribund char without ulcers from an outbreak in Farm A in October 2007. Parasitological analysis of the skin revealed Gyrodactylus spp. No parasites were found on the gills. Bacteriological analysis was only made from kidney, as there were no
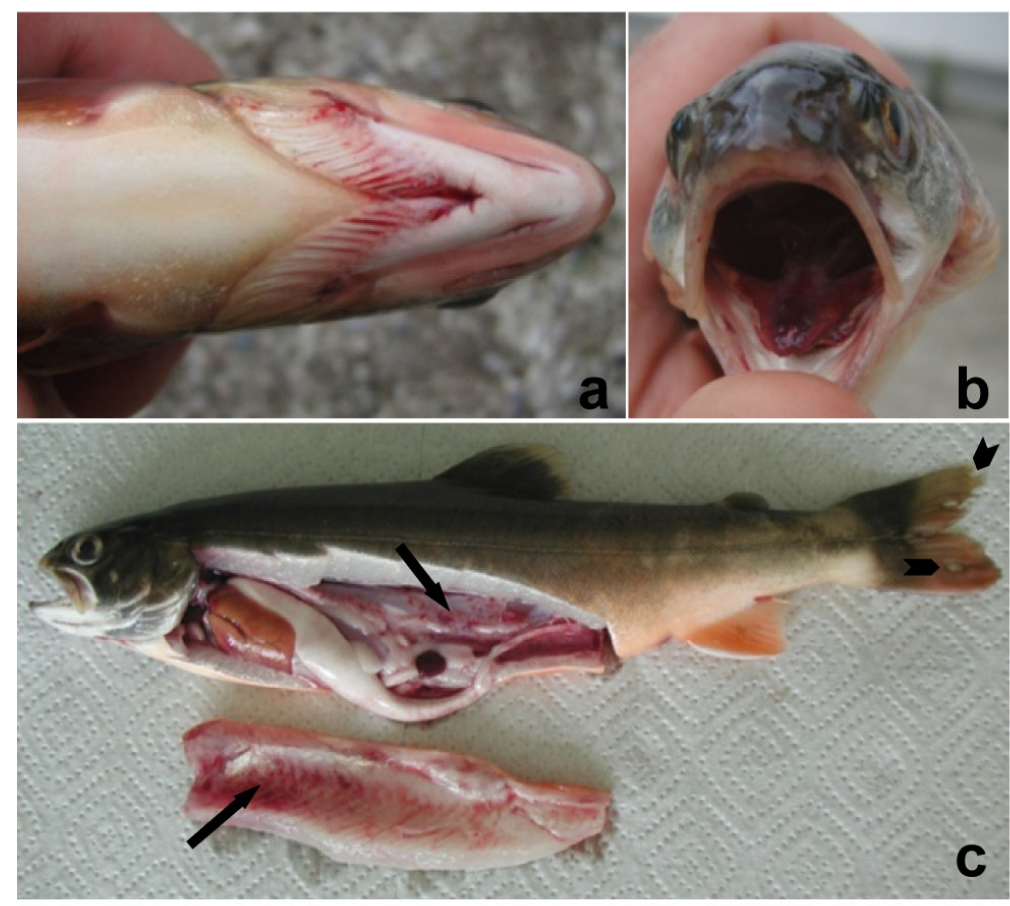

Fig. 1. Salvelinus alpinus. Clinical and pathological findings in Arctic char with haemorrhagic disease, from which Aeromonas salmonicida subsp. smithia was isolated. (a) Inflammation and haemorrhages in the ventral part of the opercula; (b) haemorrhages on tongue and in oral cavity; (c) petechiae of serosa and swim bladder (arrows), fin lesions (arrowheads) skin lesions. It revealed a high amount of slow-growing, non-haemolytic, Gram-negative bacteria forming a nearly confluent culture of uniform colonies of up to $1 \mathrm{~mm}$ diameter on tryptic soy agar plates containing $5 \%$ sheep blood (Oxoid) after 4 to $5 \mathrm{~d}$ of incubation at $18^{\circ} \mathrm{C}$. The regularity of the colonies indicated a pure culture and no other bacteria were detected. The culture was cloned, sub-cultivated and stored at $-80^{\circ} \mathrm{C}$ as strain JF4097.

Case 2 was a moribund char with minor skin ulcerations from an outbreak in Farm B in July 2008. Parasitological analysis of skin and gills was negative. Bacteriology of the skin revealed a mixed bacterial culture including Aeromonas hydrophila and the same tiny Gram-negative colonies as described from kidney in Case 1 above. Bacteriological analysis of the kidney resulted in a massive growth of slow growing, nonhaemolytic, Gram-negative bacteria forming uniform colonies identical to those from Case 1. From the homogenous pure primary culture strain JF4439 was cloned, sub-cultivated and stored at $-80^{\circ} \mathrm{C}$.

Case 3 was a moribund char with skin ulcers from Farm A in August 2008, but from a different age group that had not had any direct or water-mediated contact with Case 1. Parasitological examination of skin and kidney was negative. Skin bacteriology revealed a mixed culture including Aeromonas hydrophila. Bacteriological analysis of the kidney resulted in a massive growth of uniform tiny colonies after 4 to $5 \mathrm{~d}$ of incubation, as also seen for Cases 1 and 2, plus a small number of A. hydrophila colonies. A representative colony of the major population, which resembled those from Cases 1 and 2 was cloned, sub-cultivated and stored at $-80^{\circ} \mathrm{C}$ as strain JF4460.

The strains JF4097, JF4439 and JF4460, isolated from the 3 independent cases, were identified by rrs (16S rRNA) gene sequencing as Aeromonas salmonicida. Biochemical typing performed according to Bergey's Manual of Systematic Bacteriology (Martin-Carnahan \& Joseph 2005) determined the identity of the strains as $A$. salmonicida subsp. smithia (Table 1). They were identical among each other and showed the same biochemical profile as $A$. salmonicida subsp. smithia type strain NCIMB $13210^{\mathrm{T}}$, with the exception of fermentation of sucrose, which was positive in the type strain but negative in the field strains. It should be noted that the type strain of A. salmonicida subsp. achromogenes (NCIMB $1110^{\mathrm{T}}$ ) was $\beta$-haemolytic positive, tryptophanase (indole) negative 
Table 1. Biochemical properties of Aeromonas salmonicida subspecies type strains and field isolates. ATCC: American Type Culture Collection (Manassas, VA, USA); NCIMB: National Collection of Industrial, Marine and Food Bacteria (Aberdeen, UK)

\begin{tabular}{|c|c|c|c|c|c|c|c|}
\hline & $\begin{array}{l}\text { A. salmonicida } \\
\text { ATCC } 33658^{\mathrm{T}}\end{array}$ & $\begin{array}{l}\text { A. achromogenes } \\
\text { NCIMB } 1110^{\mathrm{T}}\end{array}$ & $\begin{array}{l}\text { A. masoucida } \\
\text { ATCC } 27013^{\mathrm{T}}\end{array}$ & $\begin{array}{c}\text { A. smithia } \\
\text { NCIMB } 13210^{\mathrm{T}}\end{array}$ & JF4097 & JF4439 & JF4460 \\
\hline$\beta$-haemolysis & + & $t^{\mathrm{a}}$ & + & - & - & - & - \\
\hline Oxidase & + & + & + & + & + & + & + \\
\hline Aesculin hydrolysis & + & - & + & - & - & - & - \\
\hline Fermentation of D-glucose & + & + & + & + & + & + & + \\
\hline Gas from D-glucose & + & - & + & - & - & - & - \\
\hline Fermentation of sucrose & - & + & + & + & - & - & _- \\
\hline Fermentation of D-mannitol & + & $t^{\mathrm{a}}$ & + & - & - & - & - \\
\hline Tryptophanase (indole) & - & $-^{a}$ & + & - & - & - & - \\
\hline Brown diffusible pigment & + & + & - & - & - & - & - \\
\hline
\end{tabular}

and D-mannitol fermentation positive in our analysis, which is in contradiction with the data given in Bergey's Manual of Systematic Bacteriology.

Sequencing of the gyrB gene revealed that the 3 strains JF4097, JF4439 and JF4460 all had the same sequence (EMBL/GenBank accession number FN394064). There was 99.89\% sequence homology with the $g y r B$ of Aeromonas salmonicida subsp. smithia type strain NCIMB $13210^{\mathrm{T}}$ (EMBL/GenBank accession number AM262159). This confirmed strains JF4097, JF4439 and JF4460 as A. salmonicida subsp. smithia. The phylogenetic tree of the $g y r B$ sequences obtained by multiple sequence alignments is shown in Fig. 2. It shows that the A. salmonicida subsp. smithia strains isolated from the 3 different outbreaks in Arctic char have a common origin and form a tight cluster with the $A$. salmonicida subsp. smithia type strain (NCIMB $13210^{\mathrm{T}}$ ), that is distinctly separated from the other A. salmonicida species.

Results of the PCR assay for Type III protein secretion genes are shown in Table 2. Two of the 3 field strains of $A$. salmonicida subsp. smithia (JF4097 and JF4439) harboured the gene asc $V$. All 3 strains possessed the toxin gene aex $T$ and the 2 virulence effector genes aopP and aopH but none of them harboured the effector gene aopO. The virulence gene profiles of strains JF4097 and JF4439 correspond to that of the type strain NCIMB13210 ${ }^{\mathrm{T}}$ previously determined (Burr \& Frey 2007).

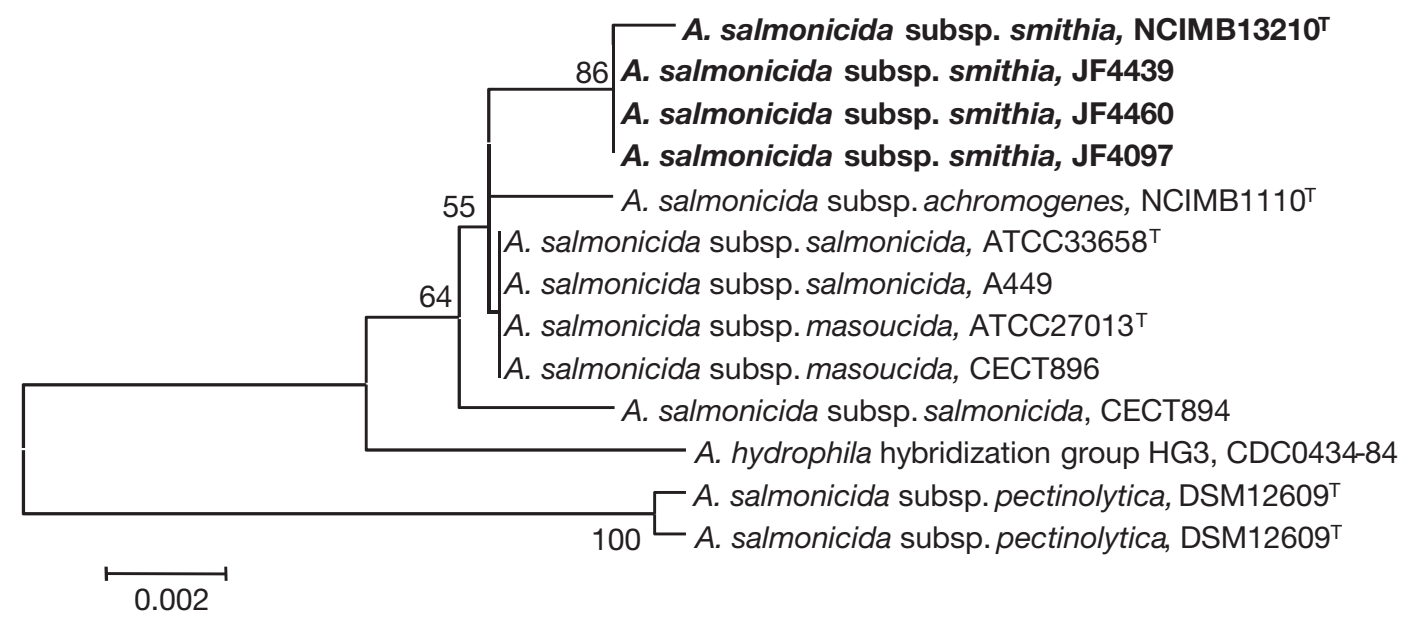

Fig. 2. Unrooted phylogenetic tree based on a fragment of $963 \mathrm{bp}$ of the gyrB gene showing the relationship of strains JF4097, JF4439 and JF4460 with other Aeromonas salmonicida strains. Numbers at nodes indicate bootstrap values (percentages of 1000 replicates). Sequence accession numbers are given in 'Materials and methods'. Scale bar $=0.2$ changes per 100 positions. ATCC: American Type Culture Collection (Manassas, VA, USA); CDC: Centers for Disease Control (Atlanta, GA, USA); CECT: Colección Española de Cultivos Tipo (Valencia, Spain); DSM: Deutsche Sammlung von Mikroorganismen und Zellkulturen (Braunschweig, Germany); NCIMB: National Collection of Industrial, Food and Marine Bacteria (Aberdeen, UK) 
Table 2. Presence of virulence factors in Aeromonas salmonicida subsp. smithia, tested by PCR. The ascV gene encodes an inner membrane component of the Type III secretion system (TTSS). Genes aexT, аорP, аорO and aopH code for effector proteins that are secreted via the TTSS. A. salmonicida subsp. salmonicida strain JF2267 (Braun et al. 2002) was used as positive control and $A$. salmonicida subsp. pectinolycita strain JF3120 (DSM 12609) as negative control

\begin{tabular}{|lcccccc|}
\hline & ascV & aexT & aopP & aоpO & aоpH \\
\hline JF2267 & + & + & + & + & + \\
JF4097 & + & + & + & - & + \\
JF4439 & + & + & + & - & + \\
JF4460 & - & + & + & - & + \\
JF3120 & - & - & - & - & - \\
\hline
\end{tabular}

\section{DISCUSSION}

Aeromonas salmonicida subsp. smithia was originally classified as a member of the family Pasteurellaceae (probably because of its very slow growth, as it takes 4 to $5 \mathrm{~d}$ for the colonies to appear on the plates, whereas other aeromonads usually grow within 1 to 2 d) and named Haemophilus piscium (Sniezko et al. 1950). It is now classified into the genus Aeromonas as A. salmonicida subsp. smithia (Paterson et al. 1980, Austin et al. 1989, 1998, Thornton et al. 1999). In spite of taxonomic uncertainties among the subspecies of $A$. salmonicida given by phenotypic identifications, genotypic methods based on $r r s, g y r B$ and $r p o B$ sequence analysis revealed reliable groupings of strains that are consistent with the taxonomic organization of Aeromonas species and have a high capacity to differentiate between species and subspecies (Yáñez et al. 2003, Küpfer et al. 2006). However, infections or epizootics caused by $A$. salmonicida subsp. smithia have rarely been reported (Wiklund \& Dalsgaard 1998), which might be due to the former misclassification and the delayed appearance of bacterial colonies on culture medium.

The current report describes 3 cases of bacterial septicaemia in Arctic char, from outbreaks in which $A$. salmonicida subsp. smithia was regularly detectable in high amounts in the kidneys. It was isolated as a pure culture in 2 cases and accompanied by a low amount of A. hydrophila in one case. Since no viral infection and no particular common parasite were identified as causative agent for the outbreaks, and due to the heavy colonization of kidney of diseased fish by $A$. salmonicida subsp. smithia, expected to result from septicaemia, we conclude that $A$. salmonicida subsp. smithia is the etiological agent of the ulcerative haemorrhagic disease. Phenotypic characterization of the 3 strains from these outbreaks revealed a discrepancy with the type strain of $A$. salmonicida subsp. smithia
NCIMB $13210^{\mathrm{T}}$ concerning sucrose fermentation. However, all 3 field strains were unambiguously identified as A. salmonicida subsp. smithia by genotypic methods, indicating that sucrose fermentation does not discriminate this subspecies since both sucrose fermentation positive and negative strains might be encountered.

The PCR results showed that the isolated strains possessed virulence genes and associated genes encoding a Type III protein secretion system. The presence of these virulence genes is a further criterion underlining the role of Aeromonas salmonicida subsp. smithia as an aetiological agent in these ulcerative and haemorrhagic disease outbreaks. The lack of ascV in one strain (JF4460) is surprising in the light of the presence of aexT, aopP and aopH genes that encode virulence factors requiring Type III secretion and translocation for their activity. We expect that the asc $V$ gene, potentially residing on a mobile genetic element, was lost during transport of the strain during summer 2008, when temperatures were above $18^{\circ} \mathrm{C}$, as it was previously shown for Type III secretion genes of certain strains of $A$. salmonicida subsp. salmonicida (Stuber et al. 2003)

In summary, virulent strains of Aeromonas salmonicida subsp. smithia, carrying Type III secretion and effector genes, were isolated as pure or almost pure cultures from diseased Arctic char. Aeromonas salmonicida subsp. smithia must therefore be considered as primary pathogens causing ulcerative and haemorrhagic disease in Arctic char Salvelinus alpinus. Its slow growth parameters under culture conditions require particular attention in bacteriological diagnostics.

Acknowledgements. This work was supported by the Swiss National Science Foundation, grant no. 3100A0-101595.

\section{LITERATURE CITED}

Austin DA, McIntosh D, Austin B (1989) Taxonomy of fish associated Aeromonas spp., with the description of Aeromonas salmonicida subs. smithia, subsp. nov. Syst Appl Microbiol 11:277-290

Austin B, Austin DA, Dalsgaard I, Gudmundsdottir BK and others (1998) Characterization of atypical Aeromonas salmonicida by different methods. Syst Appl Microbiol 21: $50-64$

Bernoth EM (1997) Furunculosis: the history of the disease and of disease research. In: Bernoth EM, Ellis AE, Midtlyng PJ, Olivier G, Smith P (eds) Furunculosis: multidisciplinary fish disease research. Academic Press, London, p $1-20$

Braun M, Stuber K, Schlatter Y, Wahli T, Kuhnert P, Frey J (2002) Characterization of an ADP-ribosyltransferase toxin (AexT) from Aeromonas salmonicida subsp. salmonicida. J Bacteriol 184:1851-1858

Burr SE, Frey J (2007) Analysis of type III effector genes in 
typical and atypical Aeromonas salmonicida. J Fish Dis 30: 711-714

Dacanay A, Knickle L, Solanky KS, Boyd JM and others (2006) Contribution of the type III secretion system (TTSS) to virulence of Aeromonas salmonicida subsp. salmonicida. Microbiology 152:1847-1856

Fehr D, Casanova C, Liverman A, Blazkova H and others (2006) AopP, a type III effector protein of Aeromonas salmonicida, inhibits the NF-kappaB signalling pathway. Microbiology 152:2809-2818

Fehr D, Burr SE, Gibert M, d'Alayer J, Frey J, Popoff MR (2007) Aeromonas exoenzyme T of Aeromonas salmonicida is a bifunctional protein that targets the host cytoskeleton. J Biol Chem 282:28843-28852

Gudmundsdottir BK (1998) Infections by atypical strains of the bacterium Aeromonas salmonicida. Buvisindi 12: 61-72

Ibrahim GF, Fleet GH, Lyons MJ, Walker RA (1985) Method for the isolation of highly purified Salmonella flagellins. J Clin Microbiol 22:1040-1044

Kuhnert P, Frey J, Lang NP, Mayfield L (2002) Phylogenetic analysis of Prevotella nigrescens, Prevotella intermedia and Porphyromonas gingivalis clinical strains reveals a clear species clustering. Int J Syst Evol Microbiol 52: 1391-1395

Küpfer M, Kuhnert P, Korczak BM, Peduzzi R, Demarta A (2006) Genetic relationships of Aeromonas strains inferred from 16S rRNA, gyrB and $r p o B$ gene sequences. Int J Syst Evol Microbiol 56:2743-2751

Martin-Carnahan A, Joseph SW (2005) Family I. Aeromonadaceae Colwell, MacDonell and De Ley 1986, $474^{\mathrm{VP}}$. In Brenner DJ, Krieg NR, Staley JT, Garrity GM (eds)

Editorial responsibility: David Bruno,

Aberdeen, UK
Bergey's manual of systematic bacteriology, 2nd edn, Vol 2, The Proteobacteria, Part B, The Gammaproteobacteria. Springer, New York, p 556-580

Munro ALS, Hastings TS (1993) Furunculosis. In: Inglis V, Roberts RJ, Bromage NR (eds) Bacterial diseases of fish. Blackwell Science, Oxford, p 122-142

Paterson WD, Douey D, Desautels D (1980) Relationships between selected strains of typical and atypical Aeromonas salmonicida, Aeromonas hydrophila, and Haemophilus piscium. Can J Microbiol 26:588-598

Singer P (2007) Fisch gegen Herzinfarkt. Umschau Buchverlag Breidenstein, Frankfurt am Main

Sniezko SF, Griffin PJ, Friddle SB (1950) A new bacterium (Hemophilus piscium n. sp.) from ulcer disease of trout. J Bacteriol 59:699-710

Stuber K, Burr SE, Braun M, Wahli T, Frey J (2003) Type III secretion genes in Aeromonas salmonicida subsp. salmonicida are located on a large thermolabile virulence plasmid. J Clin Microbiol 41:3854-3856

Thornton JM, Austin DA, Austin B, Powell R (1999) Small subunit rRNA gene sequences of Aeromonas salmonicida subsp. smithia and Haemophilus piscium reveal pronounced similarities with $A$. salmonicida subsp. salmonicida. Dis Aquat Org 35:155-158

Wiklund T, Dalsgaard I (1998) Occurrence and significance of atypical Aeromonas salmonicida in non-salmonid and salmonid fish species: a review. Dis Aquat Org 32:49-69

Yáñez MA, Catalán V, Apráiz D, Figueras MJ, MartínezMurcia AJ (2003) Phylogenetic analysis of members of the genus Aeromonas based on gyrB gene sequences. Int J Syst Evol Microbiol 53:875-883

Submitted: March 10, 2009; Accepted: June 28, 2009

Proofs received from author(s): August 31, 2009 